\title{
Aortic arch mobile masses: "Carotid-equivalent" lesions deserving aggressive surgical treatment
}

\author{
John A. Elefteriades, MD, ${ }^{a}$ and Bulat A. Ziganshin, $\mathrm{MD}^{\mathrm{a}, \mathrm{b}}$
}

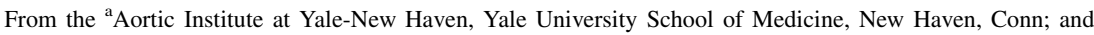

${ }^{\mathrm{b}}$ Department of Surgical Diseases \#2, Kazan State Medical University, Kazan, Russia. Disclosures: Authors have nothing to disclose with regard to commercial support.

Received for publication Jan 9, 2017; accepted for publication Jan 12, 2017; available ahead of print Feb 25, 2017. Address for reprints: John A. Elefteriades, MD, Aortic Institute at Yale-New Haven, 789 Howard Ave, Clinic Building CB317, New Haven, CT 06519 (E-mail: john.elefteriades@yale.edu).

J Thorac Cardiovasc Surg 2017;153:e85-6

0022-5223/\$36.00

Copyright (C) 2017 by The American Association for Thoracic Surgery

http://dx.doi.org/10.1016/j.jtcvs.2017.01.005
}

The article by Masaki and colleagues ${ }^{1}$ focuses attention on intraluminal aortic masses. This focus is appreciated, because few surgeons have extensive experience with these relatively unusual conditions. Concrete treatment paradigms remain elusive.

Our group has accumulated some experience with these lesions. ${ }^{2,3}$ We agree with the generally aggressive posture suggested by Masaki and colleagues, ${ }^{1}$ which has proved effective in our experience as well.

We make the following specific points about these lesions and their management:

1. Lesions in the aortic arch should be treated aggressively because of the danger for cerebral embolization. One would never delay surgically treating a mobile mass in the carotid artery by carotid endarterectomy. We need to remember that the aortic arch can be viewed as essentially the proximal portion of the carotid artery. A mobile aortic arch mural lesion is no less dangerous by virtue of originating more proximally in the vascular tree than the carotid itself. In fact, such aortic arch lesions are often perfectly suited to shed emboli to the brain (Figure 1, A). Microemboli may be detected in the resting state on transcranial Doppler, indicating ongoing active embolization. In the current era, the aortic arch can be approached safely, 4,5 justifying an aggressive surgical approach. This aggressive posture is specifically aimed at single (or localized) lesions. Diffuse, severe arteriosclerosis of the aortic arch is a different matter, often too severe for localized surgical treatment. We encourage neurologists and others caring for patients with cerebral events to remember to image the thoracic aorta to rule out causative lesions in that territory. Resection of mobile aortic arch atheromas is likely to become increasingly important in the future as transesophageal echocardiography and computed tomography lead to their more common identification as a cause of cerebral ischemic events.

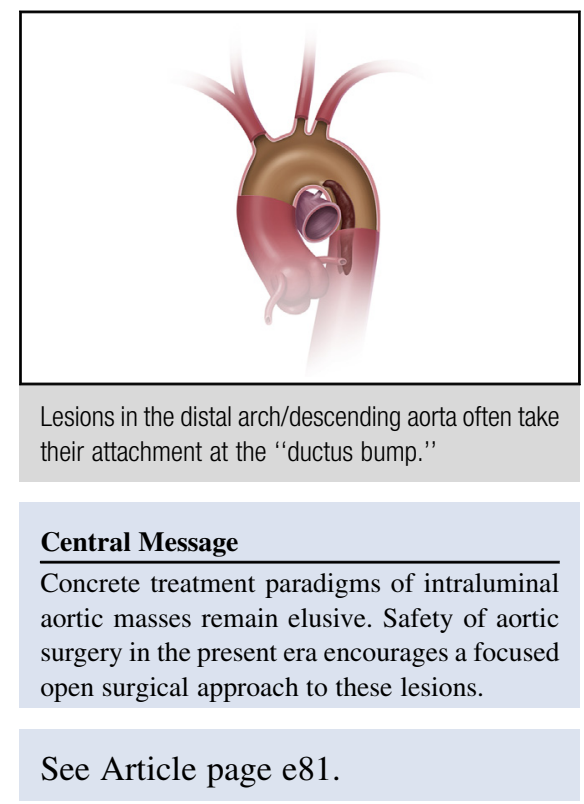

2. Arteriosclerotic lesions respond poorly to anticoagulation. These lesions are composed of atheroma, not thrombus. It has been demonstrated that the response to anticoagulation is poor, ${ }^{6,7}$ which is not surprising because atheroma would not be expected to respond. Thus, prolonged or multiagent anticoagulation without anatomic response often is not warranted or effective. Surgical resection is curative. We have patients in whom anticoagulants are added sequentially while the patient experiences repeated cerebrovascular events. We believe that aggressive surgery is more appropriate for discrete, localized lesions, especially when single or small in number.

3. The normal retrograde flow of blood in diastole means that lesions in proximity to the left subclavian artery can be responsible for cerebral emboli (even if just beyond the distal lip of the subclavian ostium) (Figure 1, B). Just because a mobile lesion seems to be located just beyond the subclavian artery does not exonerate the lesion from a causative role in stroke or transient ischemic attack, especially those in the posterior circulation related to the vertebral artery.

4. Descending aortic lesions often are thrombotic and tend to originate in the vestigial "ductus bump" (Figure 1,C). These often look like "hot dogs" dangling in the descending aorta from the region of the ductus. 


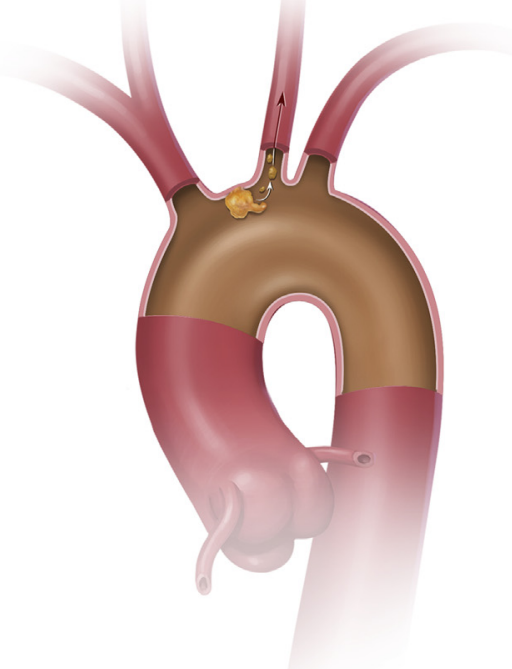

A

B
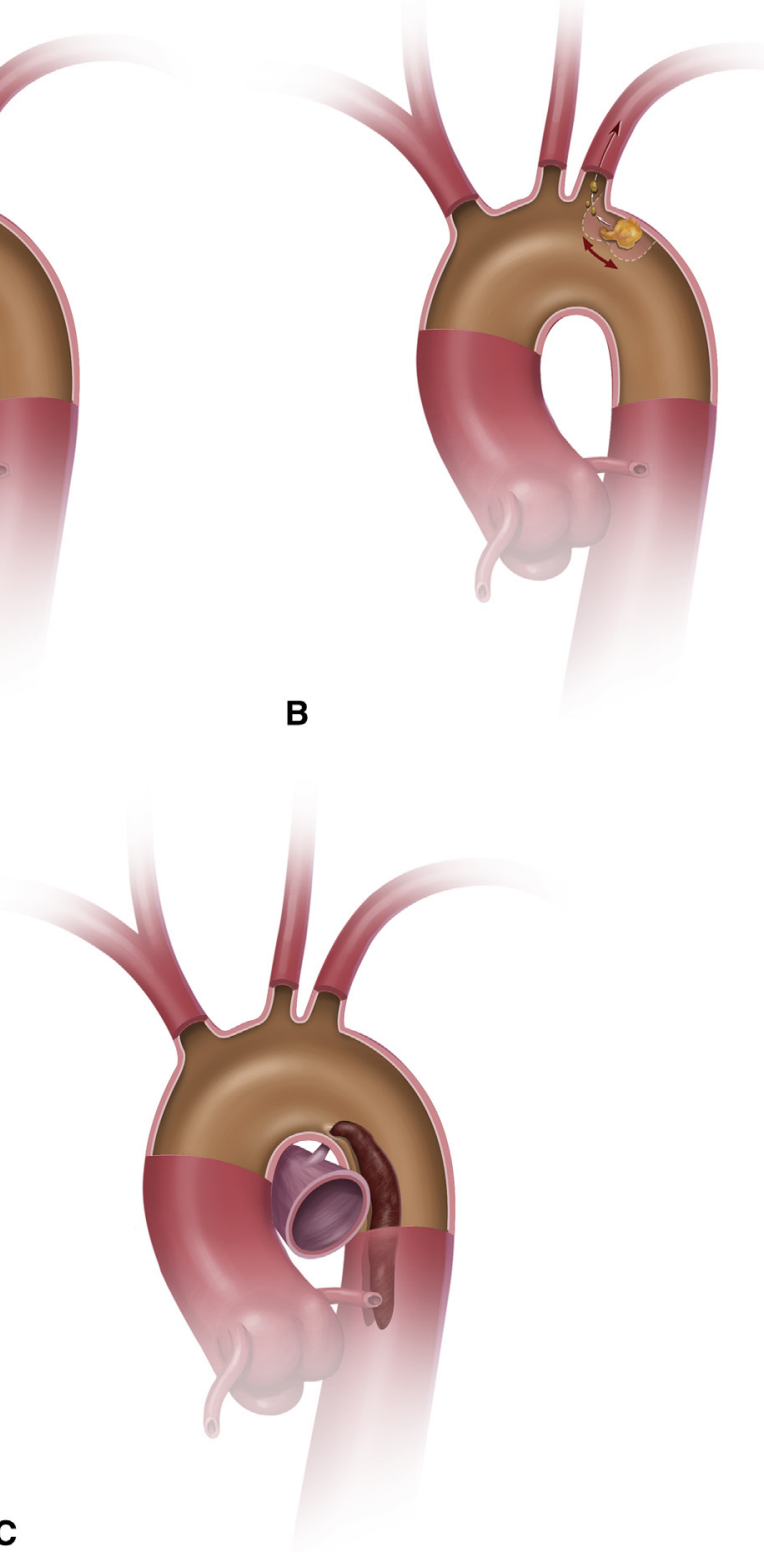

FIGURE 1. A, Arch atheromas are perfectly situated to embolize to the brain. B, Lesions just beyond the ostium of the left subclavian artery can still embolize in to the subclavian artery and the posterior cerebral circulation because of forward and backward movement (normal backward flow of blood in diastole). C, Long ("hot dog"-shaped) lesions in the descending aorta often take their attachment at the "ductus bump."

Some patients have demonstrable hypercoagulability, whereas others do not. Resection is usually extremely straightforward.

5. "Squashing" a large lesion outside a delivered endograft, while tempting, remains controversial. Potential complications are myriad, especially distal embolization and overlooking of a malignant lesion. Long-term follow-up of such endovascular treatment is limited. For most cases, open surgical therapy can be accomplished safely and conclusively.

We thank Masaki and colleagues ${ }^{1}$ for focusing our attention on the interesting and challenging topic of mobile intra-aortic masses. The safety of aortic surgery in the present era encourages a focused open surgical approach to these lesions.

\section{References}

1. Masaki N, Ogasawara T, Matsuki K. Differential diagnosis and management of a mural mass in the aortic arch. J Thorac Cardiovasc Surg. 2017;153:e81-3.

2. Modi BP, Longo MJ, Kopf GS, Elefteriades JA. Surgical management of giant descending aortic thrombus detected by transesophageal echocardiography. Int J Angio. 2000;9:243-5.

3. Lancaster GL, Lovoulos C, Moussouttas M, Goldstein AH, Leifer D, Fayad PB, et al. Aortic arch replacement for recurrent cerebral embolization. Ann Thorac Surg. 2002;73:291-4.

4. Achneck HE, Rizzo JA, Tranquilli M, Elefteriades JA. Safety of thoracic aortic surgery in the present era. Ann Thorac Surg. 2007;84:1180-5.

5. Ziganshin BA, Rajbanshi BG, Tranquilli M, Fang H, Rizzo JA, Elefteriades JA. Straight deep hypothermic circulatory arrest for cerebral protection during aortic arch surgery: safe and effective. J Thorac Cardiovasc Surg. 2014;148:888-900.

6. The French Study of Aortic Plaques in Stroke Group. Atherosclerotic disease of the aortic arch as a risk factor for recurrent ischemic stroke. $N$ Engl J Med. 1996;334:1216-21.

7. Fujimoto S, Yasaka M, Otsubo R, Oe H, Nagatsuka K, Minematsu K. Aortic arch atherosclerotic lesions and the recurrence of ischemic stroke. Stroke. 2004;35:1426-9. 